\title{
DINÁMICA DE LA OFERTA DE CARRERAS Y DE LA MATRÍCULA DE PRIMER AÑO EN DIVERSAS ÁREAS TEMÁTICAS
}

Nelson Paulus * 


\section{RESUMEN}

El presente artículo describe la forma en la cual ha evolucionado el número de programas ofrecidos en las diversas áreas temáticas, así como la matrícula de primer año de estos programas entre los años 1997 y 2001. Más allá de los naturales incrementos y decrementos que pueden ser observados, el artículo pretende constatar la heterogeneidad de las dinámicas desarrolladas por las diversas áreas temáticas al compararlas desde la óptica de diversas variables incidentes, tales como el sistema de supervisión, la región donde se ubican y el tipo de institución oferente.

\section{ABSTRACT}

This paper describes how the number of study programs offered in different subject areas has evolved, as has enrolment in the first year of these education programs during the period 19972001. Over and above the natural increases and decreases that may be observed, the paper tries to show the different dynamic trends developed in the various thematic areas by making comparisons between different influential variables such as supervision systems, the region where certain education programs are offered, and the type of educational establishment offering the programs. 


\section{DINÁMICA DE LA OFERTA DE CARRERAS Y DE LA MATRÍCULA DE PRIMER AÑO EN DIVERSAS ÁREAS TEMÁTICAS}

\section{INTRODUCCIÓN}

El Consejo Superior de Educación, a través de su Departamento de Estudios, ha realizado un análisis en torno a las cifras que la publicación I.N.D.I.C.E.S. ${ }^{1}$ pone a su disposición cada año.

Más allá de comprobar el ya conocido crecimiento en el número de carreras profesionales ofrecidas, el estudio pretende destacar la heterogeneidad observada en la evolución de las diversas áreas y subáreas temáticas, considerando que la dinámica que cada una de éstas adquiere, en términos de aumento y disminución, presenta en los últimos años características heterogéneas. También se desarrollará un contrapunto con la forma en que evoluciona la matrícula de primer año en las distintas áreas de estudios, estimada esta matrícula como el correlato sensible de la demanda con respecto a la oferta.

Se observa, además, que otras tres variables inciden en el desarrollo de estas dinámicas: la región donde se encuentran los programas mediante los cuales se articula la oferta de las diversas áreas temáticas; el tipo de institución que sustenta dicha oferta, y el sistema en que se ubican dichas instituciones. El supuesto en que se basa este estudio, considera que las variables antes mencionadas inciden en la sensibilidad y flexibilidad de respuesta que manifiesta la oferta en las diversas áreas temáticas.

El universo sobre el que recaerá este análisis está constituido por todas las carreras de nivel profesional que han ofrecido los institutos profesionales y las universidades, en las diferentes áreas

1. I.N.D.I.C.E.S.:Indicadores, números y datos sobre instituciones y carreras de educación superior. 
temáticas, entre 1997 y 2001. El dato referido a la matrícula de primer año se basa en las cifras entregadas para el mismo universo. ${ }^{2}$

\section{ÁREAS TEMÁTICAS}

El número de programas de formación profesional se ha incrementado en 403 durante los últimos cinco años, lo cual representa un aumento de un $25.8 \%$ en 2001, respecto de 1997.

\section{Tabla $\mathrm{N}^{\circ} 1$}

Crecimiento porcentual oferta de programas por área.

\begin{tabular}{|lrrr|}
\hline Área & 1997 & 2001 & $\%$ crecimiento \\
Administración y Comercio & 334 & 383 & $14,7 \%$ \\
Agropecuaria & 104 & 110 & $5,8 \%$ \\
Arte y Arquitectura & 134 & 154 & $14,9 \%$ \\
Ciencias & 68 & 96 & $41,2 \%$ \\
Ciencias sociales & 179 & 238 & $33,0 \%$ \\
Derecho & 44 & 51 & $15,9 \%$ \\
Educación & 248 & 283 & $14,1 \%$ \\
Humanidades & 55 & 58 & $5,5 \%$ \\
Salud & 62 & 90 & $45,2 \%$ \\
Tecnología & 333 & 501 & $50,5 \%$ \\
Total general & 1.561 & 1.964 & $25,8 \%$ \\
\hline
\end{tabular}

De manera similar, y como respuesta a este aumento del número de programas ofrecidos, el número de estudiantes que en el año 2001 se encontraba en primer año de estudios en las diversas carreras y áreas temáticas, supera en 35.632 a la cifra del año 1997.

2. Será estimada como la oferta del año correspondiente, el total de programas ofrecidos en un área, conforme a lo informado por las propias instituciones a fines del año inmediatamente anterior. Es decir, para estudiar la oferta de 1997, recurriremos a la información proporcionada por las instituciones a fines de 1996 para la preparación de I.N.D.I.C.E.S.- 97. En cambio en el caso de los datos de matrícula de primer año, se recurre a los antecedentes del mismo año en cuestión. 
Tabla $\mathrm{N}^{\circ} 2$

Crecimiento porcentual matrícula primer año por área.

\begin{tabular}{|lrrc|}
\hline Área & 1997 & 2001 & \% crecimiento \\
Administración y Comercio & 12.114 & 14.764 & $21,9 \%$ \\
Agropecuaria & 4.684 & 6.288 & $34,2 \%$ \\
Arte y Arquitectura & 5.851 & 8.484 & $45,0 \%$ \\
Ciencias & 2.044 & 3.597 & $76,0 \%$ \\
Ciencias sociales & 7.813 & 13.114 & $67,8 \%$ \\
Derecho & 3.970 & 5.373 & $35,3 \%$ \\
Educación & 7.158 & 11.732 & $63,9 \%$ \\
Humanidades & 1.475 & 2.070 & $40,3 \%$ \\
Salud & 3.284 & 5.573 & $69,7 \%$ \\
Tecnología & 12.955 & 25.985 & $100,6 \%$ \\
Total profesional & 61.348 & 96.980 & $25,8 \%$ \\
\hline
\end{tabular}

Cabe mencionar, sin embargo, que dicho crecimiento manifiesta dinámicas distintas en las diversas áreas temáticas. Si bien entre 1997 y 2001 crece la totalidad de estas áreas ${ }^{3}$, tanto en materia de oferta de programas de estudios profesionales como en matrícula de primer año, lo hacen a ritmos distintos, destacándose algunas que se sitúan por debajo y otras muy por encima del porcentaje de crecimiento que muestran los indicadores generales.

Mientras la totalidad de los programas ofrecidos en las diversas áreas temáticas crecía en 25,8 \% respecto del año 1997, las áreas observadas registraban comportamientos distintos. Así, por ejemplo, el área de tecnología duplica prácticamente la diferencia que presenta el general respecto de 1997, al incrementar en 50,5\% el número de programas ofrecidos.

Junto a tecnología, son las áreas de ciencias y de salud las que presentan un mayor incremento respecto de 1997 en cuanto al número de programas ofrecidos, con un crecimiento en el número de carreras ofrecidas de $41,2 \%$ y un $45,2 \%$, respectivamente.

3. Entendemos por área la agrupación de la oferta de programas de educación superior según criterios temáticos amplios, reconociendo como tales los siguientes: agropecuarias; arte y arquitectura; ciencias sociales; educación; humanidades; derecho; administración y comercio; salud; tecnología. Estas 10 áreas temáticas que utiliza el CSE se basan principalmente en la clasificación CINE (Clasificación Internacionalizada de la Educación) de la UNESCO. 
También ciencias y salud secundan al área de tecnología en cuanto a matrícula de primer año, con cifras indicadoras de un crecimiento vertiginoso. El sector general registra un incremento de $58,1 \%$, como se señaló anteriormente. De esta forma, ciencias y salud superan el indicador general por más de 10 puntos porcentuales, mientras que tecnología lo hace por más de 42 puntos de diferencia.

Por otra parte, el menor crecimiento en la oferta de programas de estudios lo presentan las áreas de humanidades y agropecuaria, con $5,5 \%$ y $5,8 \%$, respectivamente. Ello coincide con los crecimientos a menor ritmo que manifiestan dichas áreas en materia de matrícula de primer año, con $40,3 \%$ y $34,2 \%$ cada una.

Una situación interesante se observa en el área de educación, la que, en oferta de programas de estudio, manifiesta un incremento 10 puntos menor al indicador global, ubicándose como la tercera con menor ritmo de crecimiento. En cambio, en matrícula de primer año presenta un aumento superior en más de 5 puntos al que consigna el mismo indicador para el conjunto de todas las áreas. Es decir : educación va a la zaga en materia de crecimiento de la oferta de programas respecto del indicador general, pero toma la delantera en crecimiento de matrícula de primer año, demostrando que la velocidad con la cual los alumnos se incorporan a los programas de estudios de dicha área es muy superior a la forma en la cual se implementan nuevos programas. $^{4}$

En materia de oferta de nuevos programas, después del área de educación, la que manifiesta un menor ritmo de crecimiento es administración y comercio. Si bien de manera distinta al área de educación, también ésta demuestra un bajo ritmo de crecimiento en la matrícula de primer año. Para el mundo de la educación superior, que la oferta de carreras de administración y comercio crezca muy por debajo de los indicadores generales puede resultar curioso, si pensamos que éstas son disciplinas que, para su implementación, plantean requerimientos sencillos en términos de capacidad instalada.

4. Esta situación puede explicarse en virtud de la posibilidad que las carreras de educación tienen de flexibilizar su oferta de vacantes en torno a programas ya establecidos, dadas las facilidades de implementación y equipamientos que éstas representan. 
No obstante, y entrando en un terreno especulativo, puede señalarse que en este mismo elemento radica la respuesta a dicho fenómeno. Lo más probable es que, a partir de esa misma "facilidad", esta área agotó su potencial de crecimiento acelerado con anterioridad al presente análisis, realizado gracias a las cifras proporcionadas por las bases de datos I.N.D.I.C.E.S.

\section{Tabla $\mathrm{N}^{\circ} 3$}

Programas creados en el lapso 1997 - 2001.

\begin{tabular}{|lcr|}
\hline Área & Número & Participación \\
Administración y Comercio & 123 & $19,9 \%$ \\
Agropecuaria & 14 & $2,3 \%$ \\
Arte y Arquitectura & 43 & $6,9 \%$ \\
Ciencias & 17 & $2,7 \%$ \\
Ciencias sociales & 86 & $13,9 \%$ \\
Derecho & 13 & $2,1 \%$ \\
Educación & 71 & $11,5 \%$ \\
Humanidades & 12 & $1,9 \%$ \\
Salud & 25 & $4,0 \%$ \\
Tecnología & 215 & $34,7 \%$ \\
Total profesional & 619 & $100,0 \%$ \\
\hline
\end{tabular}

Previamente abordamos el crecimiento de las distintas áreas temáticas, considerando en dicho análisis las diferencias que era posible observar en materia de oferta y de matrícula de primer año en los años extremos del periodo en referencia. En estas diferencias incidían tanto las nuevas carreras como las antiguas que reactivaban su matrícula, así como las que, por cualquier razón, cerraron su oferta de matrículas.

A diferencia del análisis anterior, la Tabla 3 aborda de manera exclusiva el total de las carreras creadas en el lapso 1997-2001, descomponiendo por área la participación porcentual que a cada una de ellas le corresponde en la reconstitución del total.

Así, es posible observar que, al menos una de cada tres carreras creadas en el periodo acotado pertenece al área de tecnología, y que, a pesar del bajo ritmo de crecimiento en materia de oferta, aproximadamente 1 de cada 5 de las carreras creadas corresponde al área de administración y comercio. 
A pesar del alto ritmo de crecimiento observado tanto en materia de oferta de programas como en matrícula de primer año, menos del $7 \%$ del total de las carreras creadas en el periodo se inscribe en las áreas de ciencias y salud. Vale decir, menos de 1 de cada 10 carreras surgidas en el periodo pertenece a alguna de estas áreas.

A diferencia de la situación antes descrita, el que sólo el 1,9\% de las carreras creadas en el lapso 1997-2001 corresponda al área de humanidades, y un 2,3\% al área agropecuaria (dos de las tres participaciones porcentuales más bajas), resulta totalmente coherente con los más bajos ritmos de crecimiento registrados por ambas áreas en cuanto a la oferta de programas de estudios observados con anterioridad.

\section{SUBÁREAS}

El análisis del nivel de las subáreas podría explicar, en términos generales, la forma en que se comportan, como un todo agregado, las áreas que hemos analizado con anterioridad.

$\mathrm{Al}$ interior del área tecnología, y en cuanto a oferta de nuevos programas, pueden observarse crecimientos aún mayores que el indicador general del área, en las subáreas industrial (116,7\%), mecánica $(68,8 \%)$, así como electricidad y electrónica $(59,5 \%)$.

De manera similar, en el área de tecnología, en lo que respecta al incremento en el número de estudiantes de primer año, parte importante de este sustantivo incremento podría explicarse por el notable crecimiento del número de alumnos que estudia en primer año carreras agrupadas en las sub-áreas industrial $(236,8 \%)$ y mecánica $(328,3 \%)$.

A partir de esto, la subárea industrial consolida en casi un 20\% su participación en el área de tecnología, en materia de matrícula de primer año en casi un $20 \%$ y la subárea de mecánica en una cifra superior al $10 \%$.

No obstante lo anterior, el crecimiento vertiginoso de estas subáreas no debe hacernos perder de vista el hecho de que la subárea 
Tabla $\mathrm{N}^{\circ} 4$

Incremento de oferta de carrera y matrícula de primer año, área tecnología.

\begin{tabular}{|c|c|c|c|c|c|c|}
\hline \multirow[b]{2}{*}{ Subárea } & \multicolumn{2}{|c|}{$\begin{array}{c}\mathrm{N}^{\circ} \text { de carreras } \\
\text { ofrecidas }\end{array}$} & \multirow[b]{2}{*}{$\underset{\%}{\text { Crecimiento }}$} & \multicolumn{2}{|c|}{$\begin{array}{c}\text { Matrícula } \\
\text { de primer año }\end{array}$} & \multirow[b]{2}{*}{$\begin{array}{c}\text { Crecimiento } \\
\%\end{array}$} \\
\hline & 1997 & 2001 & & 1997 & 2001 & \\
\hline Biomédica & sin datos 1997 & 1 & & & 57 & sin datos 1997 \\
\hline Bioprocesos & 1 & 1 & $0,0 \%$ & 47 & 49 & $4,3 \%$ \\
\hline Biotecnología & 2 & 3 & $50,0 \%$ & 66 & 44 & $-33,3 \%$ \\
\hline Computación e & & & & & & \\
\hline Informática & 100 & 131 & $31,0 \%$ & 3.949 & 7.050 & $78,5 \%$ \\
\hline Eléctrica y Electrónica & 37 & 59 & $59,5 \%$ & 756 & 2.065 & $173,1 \%$ \\
\hline Industrial & 60 & 130 & $116,7 \%$ & 1.508 & 5.079 & $236,8 \%$ \\
\hline Ingeniería civil & 21 & 21 & $0,0 \%$ & 2.835 & 3.886 & $37,1 \%$ \\
\hline Mecánica & 32 & 54 & $68,8 \%$ & 650 & 2.784 & $328,3 \%$ \\
\hline Minas y Geomensura & 17 & 23 & $35,3 \%$ & 432 & 654 & $51,4 \%$ \\
\hline Obras civiles & 28 & 38 & $35,7 \%$ & 1.629 & 2.824 & $73,4 \%$ \\
\hline Quimica y Metalurgia & 24 & 26 & $8,3 \%$ & 418 & 582 & $39,2 \%$ \\
\hline Sonido y Acústica & 5 & 4 & $-20,0 \%$ & 296 & 312 & $5,4 \%$ \\
\hline Transporte y & & & & & & \\
\hline Telecomunicaciones & 6 & 10 & $66,7 \%$ & 369 & 599 & $62,3 \%$ \\
\hline Total tecnología & 333 & 501 & $50,5 \%$ & 12.955 & 25.985 & $100,6 \%$ \\
\hline
\end{tabular}

de computación e informática ha incrementado en 78,5\% su matrícula respecto del año 1997, razón por la cual su participación ha aumentado en un $27,1 \%$ del total de matriculados en primer año en el área de tecnología.

A partir de esto podemos afirmar que, de cuatro estudiantes que en el año 2001 se matricularon en el área de tecnología, al menos uno de ellos lo hizo en el área de computación e informática.

Al interior del área salud, los crecimientos más notables en cuanto al número de programas de estudios ofrecidos corresponden a las subáreas de fonoaudiología y kinesiología, con un incremento de $100 \%$ y $85,7 \%$, respectivamente. Puede observarse algo similar en lo que respecta al incremento en el número de alumnos, registrando fonoaudiología un alza de $122,6 \%$ y kinesiología de $87,8 \%$. No obstante, el crecimiento más vertiginoso en lo que respecta a la 
Tabla $\mathrm{N}^{\circ} 5$

Incremento de oferta de carrera y matrícula de primer año, área salud.

\begin{tabular}{|c|c|c|c|c|c|c|}
\hline \multirow[b]{2}{*}{ Subárea } & \multicolumn{2}{|c|}{$\begin{array}{c}\mathrm{N}^{0} \text { de carreras } \\
\text { ofrecidas }\end{array}$} & \multirow[b]{2}{*}{$\underset{\%}{\text { Crecimiento }}$} & \multicolumn{2}{|c|}{$\begin{array}{c}\text { Matrícula } \\
\text { de primer año }\end{array}$} & \multirow[b]{2}{*}{$\begin{array}{c}\text { Crecimient } \\
\%\end{array}$} \\
\hline & 1997 & 2001 & & 1997 & 2001 & \\
\hline Enfermería & 14 & 19 & $35,7 \%$ & 776 & 1.278 & $64,7 \%$ \\
\hline Fonoaudiología & 2 & 4 & $100,0 \%$ & 84 & 187 & $122,6 \%$ \\
\hline Kinesiología & 7 & 13 & $85,7 \%$ & 369 & 693 & $87,8 \%$ \\
\hline Medicina & 10 & 12 & $20,0 \%$ & 621 & 968 & $55,9 \%$ \\
\hline Nutrición y Dietética & 4 & 6 & $50,0 \%$ & 76 & 285 & $275,0 \%$ \\
\hline Obstetricia y Puericultura & 7 & 10 & $42,9 \%$ & 312 & 510 & $63,5 \%$ \\
\hline Odontología & 5 & 7 & $40,0 \%$ & 370 & 499 & $34,9 \%$ \\
\hline Química y Farmacia & 7 & 10 & $42,9 \%$ & 417 & 659 & $58,0 \%$ \\
\hline Tecnología médica & 6 & 9 & $50,0 \%$ & 259 & 494 & $90,7 \%$ \\
\hline Total salud & 62 & 90 & $45,2 \%$ & 3.284 & 5.573 & $69,7 \%$ \\
\hline
\end{tabular}

matrícula de primer año del área salud, se registra en la subárea de nutrición y dietética, con un aumento de 275\% respecto del año 1997 , a pesar de que el incremento en la oferta de sus programas sólo fue de $50 \%$.

Tabla $\mathrm{N}^{\circ} 6$

Incremento de oferta de carrera y matrícula de primer año, área ciencias.

\begin{tabular}{|c|c|c|c|c|c|c|}
\hline \multirow[b]{2}{*}{ Subárea } & \multicolumn{2}{|c|}{$\begin{array}{c}\mathrm{N}^{\circ} \text { de carreras } \\
\text { ofrecidas }\end{array}$} & \multirow[b]{2}{*}{$\begin{array}{c}\text { Crecimiento } \\
\%\end{array}$} & \multicolumn{2}{|c|}{$\begin{array}{l}\text { Matrícula } \\
\text { de primer año }\end{array}$} & \multirow[b]{2}{*}{$\begin{array}{c}\text { Crecimiento } \\
\%\end{array}$} \\
\hline & 1997 & 2001 & & 1997 & 2001 & \\
\hline Bachillerato ciencias & 5 & 7 & $40,0 \%$ & 637 & 699 & $9,7 \%$ \\
\hline Biología & 10 & 11 & $10,0 \%$ & 271 & 372 & $37,3 \%$ \\
\hline Bioquímica & 7 & 7 & $0,0 \%$ & 210 & 321 & $52,9 \%$ \\
\hline Estadística & 4 & 5 & $25,0 \%$ & 142 & 197 & $38,7 \%$ \\
\hline Física & 4 & 6 & $50,0 \%$ & 41 & 171 & $317,1 \%$ \\
\hline Geología & 3 & 3 & $0,0 \%$ & 69 & 103 & $49,3 \%$ \\
\hline Licenciatura & 5 & 9 & $80,0 \%$ & 62 & 397 & $540,3 \%$ \\
\hline Matemáticas & 7 & 9 & $28,6 \%$ & 62 & 225 & $262,9 \%$ \\
\hline Medio ambiente & 11 & 21 & $90,9 \%$ & 326 & 778 & $138,7 \%$ \\
\hline Química & 12 & 18 & $50,0 \%$ & 224 & 334 & $49,1 \%$ \\
\hline Total ciencias & 68 & 96 & $41,2 \%$ & 2.044 & 3.597 & $76,0 \%$ \\
\hline
\end{tabular}


En términos porcentuales, en el área de ciencias el incremento más destacado del número de carreras ofrecidas se encuentra en la subárea de medio ambiente. A su vez, el número de programas ofrecidos ha crecido en los últimos cinco años en 90,9\%.

En cuanto al número de alumnos que estudia primer año al interior de las carreras de ciencias el fuerte lo constituyen las subáreas de licenciatura en ciencias $(540,3 \%)$, física $(317,1 \%)$, matemáticas $(262,9 \%)$, y con un porcentaje notoriamente menor, medio ambiente $(138,7 \%)^{5}$

Tabla $\mathrm{N}^{\circ} 7$

Incremento oferta de carrera y matrícula de primer año, área agropecuaria.

\begin{tabular}{|c|c|c|c|c|c|c|}
\hline \multirow[b]{2}{*}{ Subárea } & \multicolumn{2}{|c|}{$\begin{array}{c}\mathrm{N}^{\circ} \text { de carreras } \\
\text { ofrecidas }\end{array}$} & \multirow[b]{2}{*}{$\underset{\%}{\text { Crecimiento }}$} & \multicolumn{2}{|c|}{$\begin{array}{c}\text { Matrícula } \\
\text { de primer año }\end{array}$} & \multirow[b]{2}{*}{$\begin{array}{c}\text { Crecimiento } \\
\%\end{array}$} \\
\hline & 1997 & 2001 & & 1997 & 2001 & \\
\hline Alimentos & 15 & 15 & $0,0 \%$ & 512 & 576 & $12,5 \%$ \\
\hline Ciencias agrarias & 35 & 42 & $20,0 \%$ & 1.410 & 2.157 & $53,0 \%$ \\
\hline Forestal & 24 & 23 & $-4,2 \%$ & 1.017 & 1.117 & $9,8 \%$ \\
\hline Medicina veterinaria & 7 & 8 & $14,3 \%$ & 788 & 1.460 & $85,3 \%$ \\
\hline Recursos marinos & 23 & 22 & $-4,3 \%$ & 957 & 978 & $2,2 \%$ \\
\hline Total agropecuaria & 104 & 110 & $5,8 \%$ & 4.684 & 6.288 & $34,2 \%$ \\
\hline
\end{tabular}

En cambio el área agropecuaria, tal como señalamos anteriormente, registra uno de los más bajos crecimientos en el número de carreras ofrecidas. Las subáreas forestal y recursos marinos han visto desaparecer incluso uno de los programas ofrecidos por cada una. Ello se traduce, en términos porcentuales, en un decremento de la oferta levemente superior a los cuatro puntos.

5. En la última edición de I.N.D.I.C.E.S. se integran a la categoría de licenciatura en el área de ciencias, todas aquellas que en su referencia priorizan la entrega de este grado académico, incorporando la especialidad científica sólo como mención. Por ejemplo: licenciatura en Ciencias con mención en Física. 
Tabla $\mathrm{N}^{\circ} 8$

Incremento de oferta de carrera y matrícula de primer año, área educación.

\begin{tabular}{|c|c|c|c|c|c|c|}
\hline \multirow[b]{2}{*}{ Subárea } & \multicolumn{2}{|c|}{$\begin{array}{c}\mathrm{N}^{0} \text { de carreras } \\
\text { ofrecidas }\end{array}$} & \multirow[b]{2}{*}{$\underset{\%}{\text { Crecimiento }}$} & \multicolumn{2}{|c|}{$\begin{array}{c}\text { Matrícula } \\
\text { de primer año }\end{array}$} & \multirow[b]{2}{*}{$\begin{array}{c}\text { Crecimiento } \\
\%\end{array}$} \\
\hline & 1997 & 2001 & & 1997 & 2001 & \\
\hline Educación & 6 & & $-100,0 \%$ & 79 & & $-100,0 \%$ \\
\hline Educación básica & 40 & 49 & $22,5 \%$ & 1.022 & 2.584 & $152,8 \%$ \\
\hline Educación especial & 25 & 30 & $20,0 \%$ & 869 & 1.506 & $73,3 \%$ \\
\hline Educación media & 122 & 139 & $13,9 \%$ & 2.843 & 4.548 & $60,0 \%$ \\
\hline Educación parvularia & 53 & 58 & $9,4 \%$ & 2.275 & 2.818 & $23,9 \%$ \\
\hline Licenciatura en educación & & 3 & & & 108 & \\
\hline & & & Sin datos 1997 & & & Sin datos 1997 \\
\hline Otros & 2 & 4 & $100,0 \%$ & 70 & 168 & $140,0 \%$ \\
\hline Total educación & 248 & 283 & $14,1 \%$ & 7.158 & 11.732 & $63,9 \%$ \\
\hline
\end{tabular}

En el ámbito de educación, la más fuerte arremetida tiene que ver con las carreras de educación básica que se incrementan en un $22,5 \%$, observándose un incremento aún mayor en términos del número de estudiantes que ingresan a primer año a carreras de esa subárea: 152,8\%. ${ }^{6}$ Esta situación constituye una fuerte corroboración de la idea expresada en puntos anteriores, y en la que se ha señalado el caso de aquellas carreras de fácil implementación y menores requerimientos de instalación, que pueden incrementar de manera sustantiva su matrícula de primer año, sin una variación tan significativa en el número de programas de estudios que implementan dicha matrícula.

En el área de administración y comercio se puede apreciar un franco estancamiento respecto del número de programas ofrecidos el año 1997, de manera específica en las subáreas de finanzas y contabilidad. Respecto de esta última, resulta interesante, a pesar del estancamiento ya mencionado, apreciar un leve incremento de 6,2\% en el número de alumnos respecto de 1997. Comprobar este estancamiento avala la idea de que el potencial de crecimiento

6. Hemos dejado afuera la categoría de Otros que se puede identificar en el área de educación, dada la heterogénea composición de las carreras que se ven agrupadas en ella, y su escaso número, lo cual magnifica el impacto porcentual. 
vertiginoso del área de administración y comercio se debe fundamentalmente a la subárea de contabilidad. De esta forma, lo más probable es que el potencial de expansión de esta subárea y del área en la cual se inserta se haya agotado con anterioridad al lapso que contempla nuestro análisis.

De manera complementaria se observa que, en esta área, el bajo crecimiento de la matrícula de primer año puede asociarse al franco decremento en las cifras de matrícula en las subáreas de marketing $(-20,6 \%)$ y finanzas $(-15,0 \%)$. Pese a ello, podemos apreciar un incremento porcentual en cuanto a la matrícula de primer año, cuya importancia trasciende la realidad del área en cuestión.

En términos del número de programas ofrecidos e independientemente de las áreas en que se insertan, las subáreas con los registros más altos de crecimiento, sean éstos positivos o negativos, se encuentran al interior del área de administración y comercio, en la subárea turismo y hotelería, con un incremento de $240 \%$ respecto del total de programas ofrecidos en 1997. Esta situación resulta coherente con el hecho que el número de alumnos que ingresan a primer año a carreras de turismo y hotelería prácticamente se ha quintuplicado entre 1997 y 2001. Sin embargo, el incremento más importante en materia de matrícula de primer año se registra en la subárea de licenciaturas en ciencias, donde el número de estudiantes ha aumentado en 540,3\% durante el periodo al cual nos referimos.

Tabla $\mathrm{N}^{\circ} 9$

Incremento de oferta de carrera y matrícula de primer año, área administración y comercio.

\begin{tabular}{|l|rr|r|rr|r|}
\hline & \multicolumn{2}{|c|}{$\begin{array}{c}N^{\circ} \text { de carreras } \\
\text { ofrecidas }\end{array}$} & & \multicolumn{2}{|c|}{$\begin{array}{c}\text { Matrícula } \\
\text { de primer año }\end{array}$} & \\
\hline Subárea & 1997 & 2001 & $\begin{array}{c}\text { Crecimiento } \\
\%\end{array}$ & 1997 & 2001 & $\begin{array}{c}\text { Crecimiento } \\
\%\end{array}$ \\
\hline Administración & 169 & 191 & $13,0 \%$ & 7.050 & 8.266 & $17,2 \%$ \\
Comercio & 24 & 26 & $8,3 \%$ & 435 & 572 & $31,5 \%$ \\
Contabilidad & 120 & 120 & $0,0 \%$ & 3.966 & 4.212 & $6,2 \%$ \\
Finanzas & 7 & 7 & $0,0 \%$ & 226 & 192 & $-15,0 \%$ \\
Marketing & 4 & 5 & $25,0 \%$ & 126 & 100 & $-20,6 \%$ \\
Turismo y Hotelería & 10 & 34 & $240,0 \%$ & 311 & 1.422 & $357,2 \%$ \\
Total administración & & & & & & \\
$\quad$ y comercio & 334 & 383 & $14,7 \%$ & 12.114 & 14.764 & $21,9 \%$ \\
\hline
\end{tabular}


Recursos marinos, forestal, letras, artes, música, sonido, filosofía y orientación son las subáreas que descienden en cuanto al número de programas ofrecidos, mediante los cuales se articulan las especialidades.

Respecto de la disminución del número de alumnos que ingresan cada año a las aulas, son las subáreas de ciencias religiosas, música y filosofía -además de finanzas, marketing y biotecnología- las que registran mayores decrementos: $-45,2 \%,-51,6 \%,-38,3 \%,-15,0 \%$, $-20,6 \%,-33,3 \%$, respectivamente.

\section{PARTICIPACIÓN PORCENTUAL POR ÁREAS}

En materia de su composición porcentual por área temática, la oferta total de carreras se ha mantenido más o menos igual que en 1997 , salvo en el caso de dos áreas que manifiestan cambios notables en este lapso. Según lo anotado en el apartado de áreas y subáreas, el menor crecimiento del área de administración y comercio se ha traducido en una baja sustantiva de su participación en el total de alumnos de primer año, pasando de una participación porcentual de 19,8\% de alumnos matriculados en primer año en 1997, a un 15,2\% en 2001. Es decir, hay una variación de más de cuatro puntos porcentuales en su participación, en circunstancias de que la generalidad de las áreas no ha variado positiva o negativamente su participación total en más de un punto, salvo el caso de tecnología. Esta última área ha incrementado su participación en la matrícula total de primer año en más de cinco puntos porcentuales: de 21,12\% en 1997 a 26,8 en 2001, hecho todavía más notable que la baja porcentual observada en el área de administración y comercio.

En materia de oferta de programas, el estudio de los aspectos más notables se relaciona con la disminución de la participación del área de administración y comercio (de $21,4 \%$ a $19,5 \%$, menos impactante que lo observado en materia de oferta), y con el claro incremento de la participación del área de tecnología (de 21,3\% a $25,5 \%)$. 

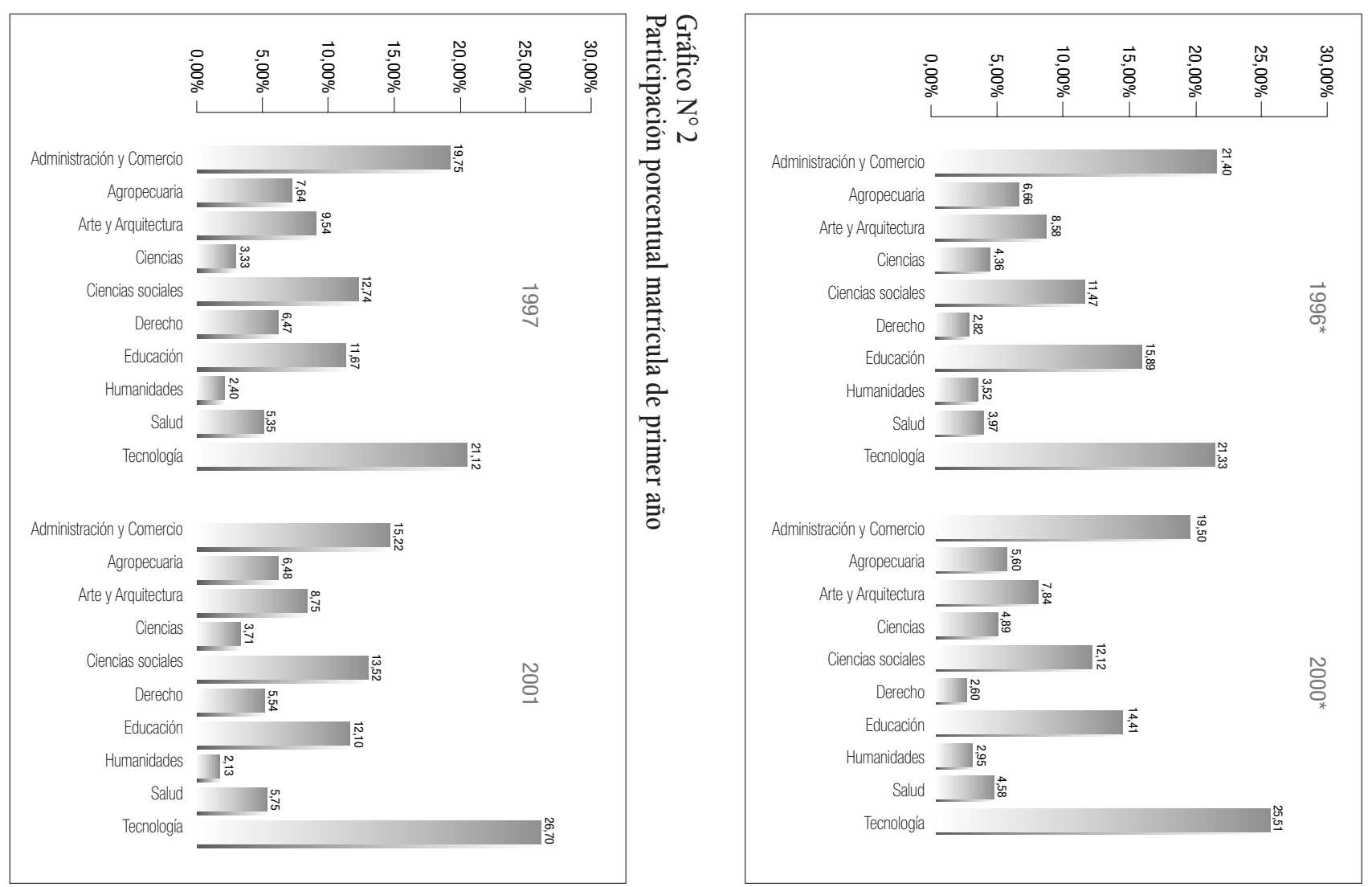

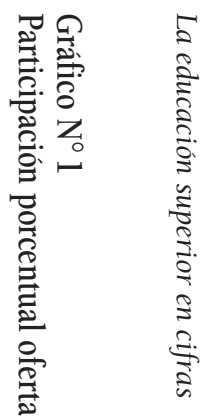




\section{TIPOS DE INSTITUCIÓN OFERENTE}

Al introducir en el análisis la variable del tipo de institución que ofrece las carreras (universidades e institutos profesionales) y la forma en que ésta incide en la evolución del número de programas ofrecidos, quisiéramos recordar ante todo algunos hechos ampliamente conocidos:

Primero: el monopolio natural de las universidades para dictar carreras profesionales en las áreas del derecho y de la salud, el cual es respaldado por la Ley Orgánica Constitucional de Enseñanza (LOCE).

Segundo: la fuerte preponderancia de la universidad en algunas áreas en que la participación de los institutos profesionales es marginal y en virtud de circunstancias específicas. Por ejemplo, en el área de humanidades, la participación de los institutos profesionales se explica sólo a partir de algunas carreras de traducción y otras como teología pastoral. En el área de educación, la participación de los institutos profesionales se explica principalmente a partir de carreras de educación que, en virtud de lo dispuesto en la LOCE, pueden ofrecerse en las mismas condiciones con que se crearon previamente a dicha ley (es decir, sin licenciatura), además de algunas que se agrupan sólo tangencialmente como carreras de educación, en la subárea "otros."

Luego de estas consideraciones preliminares, podemos observar lo siguiente: el fuerte crecimiento en el número de carreras en el área de tecnología se debe en parte importante al aumento en el número de carreras que ofrecen los institutos profesionales, que incrementan la oferta de carreras en un $157,9 \%$, frente al aumento más bien conservador del número de programas que ofrecen las universidades en el área de tecnología (11,8\%). Este fuerte incremento se debe en gran medida a la formulación de nuevos programas de estudios, bajo la modalidad de "ingeniería de ejecución" y especialmente en las subáreas.

Igual disparidad, aunque con mayores matices, puede observarse en el ámbito de las ciencias sociales, donde la oferta de los institutos profesionales es de un $60,8 \%$, frente a un $21,8 \%$ de la oferta 
Tabla 10

Incremento en la oferta de carreras, según tipo de institución oferente, respecto de 1997.

\begin{tabular}{|c|c|c|}
\hline Crecimiento $\%$ oferta de carreras & & \\
\hline ÁREA & Tipo Institución & 2001 \\
\hline ADMINISTRACIÓN Y COMERCIO & $\begin{array}{l}\text { Institutos profesionales } \\
\text { Universidades }\end{array}$ & $\begin{array}{l}19,50 \% \\
10,29 \%\end{array}$ \\
\hline Total ADMINISTRACIÓN Y COMERCIO & & $14,67 \%$ \\
\hline AGROPECUARIA & $\begin{array}{l}\text { Institutos profesionales } \\
\text { Universidades }\end{array}$ & $\begin{array}{r}-10,00 \% \\
9,52 \%\end{array}$ \\
\hline Total AGROPECUARIA & & $5,77 \%$ \\
\hline ARTE Y ARQUITECTURA & $\begin{array}{l}\text { Institutos profesionales } \\
\text { Universidades }\end{array}$ & $\begin{array}{r}32,00 \% \\
4,76 \%\end{array}$ \\
\hline Total ARTE Y ARQUITECTURA & & $14,93 \%$ \\
\hline CIENCIAS & $\begin{array}{l}\text { Institutos profesionales } \\
\text { Universidades }\end{array}$ & $\begin{array}{r}600,00 \% \\
32,84 \%\end{array}$ \\
\hline Total CIENCIAS & & $41,18 \%$ \\
\hline CIENCIAS SOCIALES & $\begin{array}{l}\text { Institutos profesionales } \\
\text { Universidades }\end{array}$ & $\begin{array}{l}60,78 \% \\
21,88 \%\end{array}$ \\
\hline Total CIENCIAS SOCIALES & & $32,96 \%$ \\
\hline DERECHO & Universidades & $15,91 \%$ \\
\hline Total DERECHO & & $15,91 \%$ \\
\hline EDUCACIÓN & $\begin{array}{l}\text { Institutos profesionales } \\
\text { Universidades }\end{array}$ & $\begin{array}{r}2,13 \% \\
16,92 \%\end{array}$ \\
\hline Total EDUCACIÓN & & $14,11 \%$ \\
\hline HUMANIDADES & $\begin{array}{l}\text { Institutos profesionales } \\
\text { Universidades }\end{array}$ & $\begin{array}{r}-9,09 \% \\
9,09 \%\end{array}$ \\
\hline Total HUMANIDADES & & $5,45 \%$ \\
\hline SALUD & Universidades & $45,16 \%$ \\
\hline Total SALUD & & $45,16 \%$ \\
\hline TECNOLOGÍA & $\begin{array}{l}\text { Institutos profesionales } \\
\text { Universidades }\end{array}$ & $\begin{array}{r}157,95 \% \\
11,84 \%\end{array}$ \\
\hline Total TECNOLOGÍA & & $50,45 \%$ \\
\hline Total Profesional & & $25,82 \%$ \\
\hline
\end{tabular}

universitaria. Esta disparidad puede explicarse por el crecimiento superior al $100 \%$ en la oferta de programas de trabajo social de los institutos profesionales, que se ofrecen sin licenciatura. ${ }^{7}$

7. Por lo demás, la carrera de Trabajo social no se encuentra dentro del grupo de carreras que, según la LOCE, requieren de licenciatura, y que en estas circunstancias se convierten en carreras de monopolio universitario. 
Tabla 11

Incremento en la matrícula de primer año, según tipo de institución oferente, respecto a 1997.

\begin{tabular}{|ll|r|}
\hline Crecimiento \% matrícula de primer año & \multicolumn{2}{l}{} \\
\cline { 1 - 2 } AREA & Tipo Institución & 2001 \\
ADMINISTRACIÓN Y COMERCIO & Institutos profesionales & $63,26 \%$ \\
& Universidades & $8,09 \%$ \\
Total ADMINISTRACIÓN Y COMERCIO & & $21,88 \%$ \\
AGROPECUARIA & Institutos profesionales & $34,15 \%$ \\
& Universidades & $34,25 \%$ \\
Total AGROPECUARIA & Institutos profesionales & $34,24 \%$ \\
ARTE Y ARQUITECTURA & Universidades & $46,80 \%$ \\
& & $44,19 \%$ \\
Total ARTE Y ARQUITECTURA & Institutos profesionales & $45,00 \%$ \\
CIENCIAS & Universidades & 6 atos 1997 \\
& & $66,14 \%$ \\
Total CIENCIAS & Institutos profesionales & $75,98 \%$ \\
CIENCIAS SOCIALES & Universidades & $110,20 \%$ \\
& Universidades & $56,70 \%$ \\
Total CIENCIAS SOCIALES & & $67,85 \%$ \\
DERECHO & Institutos profesionales & $35,34 \%$ \\
Total DERECHO & Universidades & $35,34 \%$ \\
EDUCACIÓN & & $47,53 \%$ \\
& Institutos profesionales & $68,16 \%$ \\
Total EDUCACIÓN & Universidades & $63,90 \%$ \\
HUMANIDADES & & $60,43 \%$ \\
& Universidades & $40,34 \%$ \\
Total HUMANIDADES & & $69,70 \%$ \\
SALUD & Institutos profesionales & $69,70 \%$ \\
Total SALUD & Universidades & $327,88 \%$ \\
TECNOLOGÍA & & $48,05 \%$ \\
& & $100,58 \%$ \\
Total TECNOLOGÍA & & $58,08 \%$ \\
\hline
\end{tabular}

El incremento de un $600 \%$ en las carreras que ofrecen los institutos profesionales en el área de ciencias se explica a partir de los bajos números iniciales de esta oferta, que se remite exclusivamente a carreras sin licenciatura en el área de las ciencias ambientales: de una carrera en 1997 a siete en el año 2001. 
En la evolución de la matrícula se comprueba nuevamente un fuerte incremento en el área tecnología, a partir del crecimiento de la matrícula de primer año en los institutos profesionales, presumiblemente en las mismas subáreas señaladas para el caso de las ofertas de programas: mecánica, industrial, eléctrica y electrónica, así como computación e informática.

En el área de las ciencias sociales son probablemente las carreras de trabajo social dictadas por institutos profesionales la causa del fuerte repunte que estos últimos experimentan en el rubro. Por su parte, en el área agropecuaria el crecimiento de la matrícula de primer año es bastante similar en los institutos profesionales y en las universidades. Sin embargo, la base en torno a la cual se explica este crecimiento reconoce fundamentos distintos: en los institutos profesionales, se trata principalmente de alumnos que se incorporan a ingenierías de ejecución del ámbito agrícola o acuícola, mientras que en las universidades dicha base se amplía a otras áreas tales como la medicina veterinaria, las especialidades forestales, etcétera.

Parte importante del aumento de la oferta de programas de los institutos profesionales en el área de administración y comercio se debe a la explosión de carreras con formato de ingeniería de ejecución en el área de administración, particularmente aquellas con especificidad en turismo y hotelería .

\section{PARTICIPACIÓN POR SECTOR}

En cuanto a la participación porcentual de las diversas áreas temáticas observadas en torno a los distintos sistemas de supervisión existentes, es posible señalar que, si bien las instituciones tradicionales y derivadas mantienen generalmente cifras similares de participación, también se registran algunos cambios dignos de destacar. Obviamente se observan descensos en la participación de instituciones que se encuentran en proceso de acreditación y examen, así como el progresivo paso de éstas, con toda su oferta de programas, al sector autónomo privado, tras obtener su autonomía. 
Tabla $\mathrm{N}^{\circ} 12$

Participación de oferta de programas descompuesto por areas (selección) y sistemas de supervisión

\begin{tabular}{|c|c|c|c|}
\hline Participación \% oferta de carreras & & & \\
\hline ÁREA & Sistema & 1997 & 2001 \\
\hline ADMINISTRACIÓN Y COMERCIO & $\begin{array}{l}\text { ACREDITADA, CSE } \\
\text { AUTÓNOMA DERIVADA } \\
\text { AUTÓNOMA PRIVADA } \\
\text { AUTÓNOMA TRADICIONAL } \\
\text { EXAMINADA }\end{array}$ & $\begin{array}{r}38,62 \% \\
11,68 \% \\
19,46 \% \\
7,19 \% \\
23,05 \%\end{array}$ & $\begin{array}{r}23,50 \% \\
11,49 \% \\
45,95 \% \\
5,74 \% \\
13,32 \%\end{array}$ \\
\hline Total ADMINISTRACIÓNYCOMERCIO & $100,00 \%$ & $100,00 \%$ & \\
\hline CIENCIAS SOCIALES & $\begin{array}{l}\text { ACREDITADA, CSE } \\
\text { AUTÓNOMA DERIVADA } \\
\text { AUTÓNOMA PRIVADA } \\
\text { AUTÓNOMA TRADICIONAL } \\
\text { EXAMINADA }\end{array}$ & $\begin{array}{l}45,25 \% \\
11,73 \% \\
12,29 \% \\
13,41 \% \\
17,32 \%\end{array}$ & $\begin{array}{r}23,11 \% \\
9,24 \% \\
44,54 \% \\
9,66 \% \\
13,45 \%\end{array}$ \\
\hline Total CIENCIAS SOCIALES & & $100,00 \%$ & $100,00 \%$ \\
\hline TECNOLOGÍA & $\begin{array}{l}\text { ACREDITADA, CSE } \\
\text { AUTÓNOMA DERIVADA } \\
\text { AUTÓNOMA PRIVADA } \\
\text { AUTÓNOMA TRADICIONAL } \\
\text { EXAMINADA }\end{array}$ & $\begin{array}{l}15,32 \% \\
30,33 \% \\
14,41 \% \\
28,53 \% \\
11,41 \%\end{array}$ & $\begin{array}{r}8,58 \% \\
21,16 \% \\
46,51 \% \\
20,56 \% \\
3,19 \%\end{array}$ \\
\hline Total TECNOLOGÍA & & $100,00 \%$ & $100,00 \%$ \\
\hline
\end{tabular}

El sector en proceso de acreditación, como representante del sector sometido a supervisión, manifiesta fuertes decrementos en su participación en las áreas de administración y comercio (de 38,6\% a $23,5 \%$ del área), ciencias sociales (de $45,3 \%$ a $23,11 \%$ ) y tecnología (de $15,3 \%$ a $8,58 \%$ ). Descensos similares se registran en el sector que está siendo examinado.

En las mismas áreas es posible comprobar un aumento de la participación en la oferta de carreras de las instituciones autónomas privadas, con un alza de 19,5\% a 45,9\% en administración y comercio; de $12,3 \%$ a $44,5 \%$ en ciencias sociales; y de $14,4 \%$ a $46,5 \%$ en el área de tecnología. 
Resulta interesante detenerse en la baja de participación que las instituciones tradicionales han manifestado en cuanto a oferta de programas. Respecto de las instituciones derivadas, hay un descenso de 30,3\% en 1997 a 21,2\% en 2001, en la participación en la oferta de carreras de tecnología. Las instituciones autónomas tradicionales exhiben bajas importantes en las áreas de ciencias sociales (de 13,4\% a $9,7 \%$ ) y en tecnología (de $28,5 \%$ a $20,6 \%$ ).

La pérdida de participación en dichas áreas puede deberse al crecimiento sustantivo en la oferta de programas de las instituciones de autonomía reciente. Al obtener dicha autonomía, además de traspasar el total de su oferta al sector autónomo privado, algunas instituciones incrementan esta oferta desarrollando lógicas expansivas. Ello incrementa el número total mediante el cual se calcula la participación, y determina que las instituciones autónomas derivadas y tradicionales, con lógicas expansivas menos explosivas y más conservadoras, pierdan participación respecto a los nuevos totales observados.

El hecho de que no se observen bajas importantes en el área de administración y comercio por parte de los sectores autónomos tradicionales y derivados, se explica en virtud de que esta área, como sostuvimos anteriormente, puede haber agotado su potencial de expansión en un momento previo al lapso que acota el estudio.

La baja en participación respecto a la matrícula de primer año en los sectores autónomos tradicionales y derivados puede explicarse mediante un análisis similar.

Recurriendo a las mismas áreas de referencia utilizadas para analizar la participación en la oferta de programas, podemos comprobar el decremento del sector en acreditación en las siguientes áreas: administración y comercio (de 36,6\% a $12,2 \%$ del total del área); ciencias sociales (de 48,6 \% a 12,3\%) y tecnología (de 19,7\% a 4,5\%).

Asimismo, el crecimiento de la matrícula de primer año del sector autónomo privado en las áreas de administración y comercio fue de $20,4 \%$ a $51,2 \%$ del total del área. En ciencias sociales, de 16,2\% a $60,8 \%$ y en tecnología de $12,6 \%$ a $46,9 \%$.

Nuevamente no hay cambios de participación sustantivos en los sectores autónomos derivados y tradicionales en el área de 
Tabla $\mathrm{N}^{\circ} 13$

Participación porcentual matrícula primer año según áreas (selección) y sistemas de supervisión

\begin{tabular}{|l|l|r|r|}
\cline { 1 - 2 } Participación \% matrícula de primer año & \multicolumn{2}{|l}{} \\
\cline { 1 - 2 } ÁREA & C_SIS & 1997 & 2001 \\
ADMINISTRACIÓN Y COMERCIO & ACREDITADA, CSE & $36,93 \%$ & $12,20 \%$ \\
& AUTÓNOMA DERIVADA & $17,91 \%$ & $17,99 \%$ \\
& AUTÓNOMA PRIVADA & $20,42 \%$ & $51,19 \%$ \\
& AUTÓNOMA TRADICIONAL & $13,22 \%$ & $13,71 \%$ \\
& EXAMINADA & $11,52 \%$ & $4,92 \%$ \\
\hline Total ADMINISTRACIÓNYCOMERCIO & & $100,00 \%$ & $100,00 \%$ \\
\hline \multirow{2}{*}{ CIENCIAS SOCIALES } & ACREDITADA, CSE & $48,61 \%$ & $12,34 \%$ \\
& AUTÓNOMA DERIVADA & $9,70 \%$ & $8,59 \%$ \\
& AUTÓNOMA PRIVADA & $16,19 \%$ & $60,79 \%$ \\
& AUTÓNOMA TRADICIONAL & $14,25 \%$ & $11,58 \%$ \\
& EXAMINADA & $11,25 \%$ & $6,70 \%$ \\
\hline Total CIENCIAS SOCIALES & & $100,00 \%$ & $100,00 \%$ \\
\hline \multirow{2}{*}{ TECNOLOGÍA } & ACREDITADA, CSE & $19,69 \%$ & $4,51 \%$ \\
& AUTÓNOMA DERIVADA & $31,10 \%$ & $21,41 \%$ \\
& AUTÓNOMA PRIVADA & $12,56 \%$ & $46,93 \%$ \\
& AUTÓNOMA TRADICIONAL & $31,59 \%$ & $25,28 \%$ \\
& EXAMINADA & $5,06 \%$ & $1,87 \%$ \\
\hline \multirow{2}{*}{ Total TECNOLOGÍA } & & $100,00 \%$ & $100,00 \%$ \\
\hline
\end{tabular}

administración y comercio, pero sí bajas notorias en ciencias sociales y tecnología. El sector derivado, por ejemplo, baja en el área de tecnología de $31,1 \%$ a una participación de $21,4 \%$, mientras que el sector tradicional desciende tanto en el área tecnológica como de ciencias sociales (de $31,6 \%$ a $25,3 \%$ y de $14,3 \%$ a $11,6 \%$, respectivamente).

\section{REGIONES}

En cuanto a las regiones, sólo algunas de ellas muestran cambios dignos de destacar en cuanto a la oferta de participación de programas, que se registra de manera heterogénea en diversas áreas temáticas. 
Tabla 14

Participación porcentual en la oferta de carreras, según áreas y regiones ${ }^{7}$

\begin{tabular}{|c|cc|}
\hline $\begin{array}{c}\text { Oferta } \\
\text { Programas }\end{array}$ & \multicolumn{2}{|c|}{ Administración y Comercio } \\
\hline REGIÓN & 1997 & 2001 \\
\hline 5 & $14,7 \%$ & $12,3 \%$ \\
8 & $12,3 \%$ & $15,1 \%$ \\
9 & $3,0 \%$ & $4,2 \%$ \\
13 & $47,0 \%$ & $45,7 \%$ \\
\hline Total & $100,00 \%$ & $100,00 \%$ \\
Profesional & & \\
\hline Matrícula $1^{\circ}$ & Administración y Comercio \\
\hline REGIÓN & 1997 & 2001 \\
\hline 5 & $8,26 \%$ & $9,13 \%$ \\
8 & $9,87 \%$ & $10,84 \%$ \\
9 & $2,45 \%$ & $4,23 \%$ \\
13 & $63,92 \%$ & $56,85 \%$ \\
\hline Total & $100,00 \%$ & $100,00 \%$ \\
Profesional & & \\
\hline
\end{tabular}

\begin{tabular}{|c|c|c|}
\hline $\begin{array}{c}\text { Oferta } \\
\text { Programas }\end{array}$ & \multicolumn{2}{|c|}{ Arte y Arquitectura } \\
\hline REGIÓN & 1997 & 2001 \\
\hline 5 & $17,2 \%$ & $17,5 \%$ \\
\hline 8 & $9,0 \%$ & $7,1 \%$ \\
\hline 9 & $6,0 \%$ & $3,2 \%$ \\
\hline 13 & $59,7 \%$ & $63,6 \%$ \\
\hline $\begin{array}{l}\text { Total } \\
\text { Profesional }\end{array}$ & $100,00 \%$ & $100,00 \%$ \\
\hline Matrícula $1^{\circ}$ & \multicolumn{2}{|c|}{ Arte y Arquitectura } \\
\hline REGIÓN & 1997 & 2001 \\
\hline 5 & $13,81 \%$ & $14,57 \%$ \\
\hline 8 & $8,58 \%$ & $7,96 \%$ \\
\hline 9 & $3,49 \%$ & $5,56 \%$ \\
\hline 13 & $67,42 \%$ & $63,84 \%$ \\
\hline $\begin{array}{l}\text { Total } \\
\text { Profesional }\end{array}$ & $100,00 \%$ & $100,00 \%$ \\
\hline
\end{tabular}

\begin{tabular}{|c|c|c|}
\hline $\begin{array}{c}\text { Oferta } \\
\text { Programas }\end{array}$ & \multicolumn{2}{|c|}{ Agropecuaria } \\
\hline REGIÓN & 1997 & 2001 \\
\hline 5 & $12,5 \%$ & $13,6 \%$ \\
\hline 8 & $19,2 \%$ & $15,5 \%$ \\
\hline 9 & $10,6 \%$ & $9,1 \%$ \\
\hline 13 & $29,8 \%$ & $29,1 \%$ \\
\hline $\begin{array}{l}\text { Total } \\
\text { Profesional }\end{array}$ & $100,00 \%$ & $100,00 \%$ \\
\hline Matrícula $1^{\circ}$ & \multicolumn{2}{|c|}{ Agropecuaria } \\
\hline REGIÓN & 1997 & 2001 \\
\hline 5 & $11,85 \%$ & $7,47 \%$ \\
\hline 8 & $10,50 \%$ & $14,03 \%$ \\
\hline 9 & $5,53 \%$ & $8,17 \%$ \\
\hline 13 & $44,62 \%$ & $43,19 \%$ \\
\hline $\begin{array}{l}\text { Total } \\
\text { Profesional }\end{array}$ & $100,00 \%$ & $100,00 \%$ \\
\hline
\end{tabular}

\begin{tabular}{|c|c|c|}
\hline $\begin{array}{c}\text { Oferta } \\
\text { Programas }\end{array}$ & \multicolumn{2}{|c|}{ Ciencias } \\
\hline REGIÓN & 1997 & 2001 \\
\hline 5 & $23,5 \%$ & $24,0 \%$ \\
\hline 8 & $14,7 \%$ & $11,5 \%$ \\
\hline 9 & $7,4 \%$ & $4,2 \%$ \\
\hline 13 & $42,6 \%$ & $42,7 \%$ \\
\hline $\begin{array}{l}\text { Total } \\
\text { Profesional }\end{array}$ & $100,00 \%$ & $100,00 \%$ \\
\hline Matrícula $1^{\circ}$ & \multicolumn{2}{|c|}{ Ciencias } \\
\hline REGIÓN & 1997 & 2001 \\
\hline 5 & $22,60 \%$ & $24,94 \%$ \\
\hline 8 & $5,92 \%$ & $15,23 \%$ \\
\hline 9 & $3,47 \%$ & $5,17 \%$ \\
\hline 13 & $57,05 \%$ & $47,35 \%$ \\
\hline $\begin{array}{l}\text { Total } \\
\text { Profesional }\end{array}$ & $100,00 \%$ & $100,00 \%$ \\
\hline
\end{tabular}

7. La diferencia existente entre la suma de las regiones analizadas y el 100\%, está dada por la suma de los valores del resto de las regiones. 


\begin{tabular}{|c|cc|}
\hline $\begin{array}{c}\text { Oferta } \\
\text { Programas }\end{array}$ & \multicolumn{2}{|c|}{ Ciencias Sociales } \\
\hline REGIÓN & 1997 & 2001 \\
\hline 5 & $11,2 \%$ & $10,5 \%$ \\
8 & $10,6 \%$ & $10,5 \%$ \\
9 & $6,1 \%$ & $6,3 \%$ \\
13 & $58,1 \%$ & $52,1 \%$ \\
\hline Total & $100,00 \%$ & $100,00 \%$ \\
Profesional & & \\
\hline Matrícula $1^{\circ}$ & Ciencias sociales \\
\hline REGIÓN & 1997 & 2001 \\
\hline 5 & $9,86 \%$ & $10,26 \%$ \\
8 & $7,63 \%$ & $10,07 \%$ \\
9 & $3,67 \%$ & $5,69 \%$ \\
13 & $63,54 \%$ & $58,93 \%$ \\
\hline Total & $100,00 \%$ & $100,00 \%$ \\
Profesional & & \\
\hline
\end{tabular}

\begin{tabular}{|c|c|c|}
\hline $\begin{array}{c}\text { Oferta } \\
\text { Programas }\end{array}$ & \multicolumn{2}{|c|}{ Humanidades } \\
\hline REGIÓN & 1997 & 2001 \\
\hline 5 & $25,5 \%$ & $19,0 \%$ \\
\hline 8 & $5,5 \%$ & $6,9 \%$ \\
\hline 9 & $1,8 \%$ & $1,7 \%$ \\
\hline 13 & $60,0 \%$ & $65,5 \%$ \\
\hline $\begin{array}{l}\text { Total } \\
\text { Profesional }\end{array}$ & $100,00 \%$ & $100,00 \%$ \\
\hline Matrícula $1^{\circ}$ & \multicolumn{2}{|c|}{ Humanidades } \\
\hline REGIÓN & 1997 & 2001 \\
\hline 5 & $20,54 \%$ & $16,57 \%$ \\
\hline 8 & $1,69 \%$ & $5,27 \%$ \\
\hline 9 & $2,58 \%$ & $2,03 \%$ \\
\hline 13 & $73,56 \%$ & $60,97 \%$ \\
\hline $\begin{array}{l}\text { Total } \\
\text { Profesional }\end{array}$ & $100,00 \%$ & $100,00 \%$ \\
\hline
\end{tabular}

\begin{tabular}{|c|cc|}
\hline $\begin{array}{c}\text { Oferta } \\
\text { Programas }\end{array}$ & \multicolumn{2}{|c|}{ Derecho } \\
\hline REGIÓN & 1997 & 2001 \\
\hline 5 & $11,4 \%$ & $13,7 \%$ \\
8 & $9,1 \%$ & $7,8 \%$ \\
9 & $6,8 \%$ & $5,9 \%$ \\
13 & $54,5 \%$ & $54,9 \%$ \\
\hline Total & $100,00 \%$ & $100,00 \%$ \\
Profesional & \multicolumn{2}{|c|}{} \\
\hline Matrícula $1^{\circ}$ & \multicolumn{2}{|c|}{ Derecho } \\
\hline REGIÓN & 1997 & 2001 \\
\hline 5 & $12,59 \%$ & $11,26 \%$ \\
8 & $6,78 \%$ & $8,64 \%$ \\
9 & $6,07 \%$ & $7,00 \%$ \\
13 & $60,73 \%$ & $58,83 \%$ \\
\hline Total & $100,00 \%$ & $100,00 \%$ \\
Profesional & & \\
\hline
\end{tabular}

\begin{tabular}{|c|cc|}
\hline $\begin{array}{c}\text { Oferta } \\
\text { Programas }\end{array}$ & \multicolumn{2}{|c|}{ Salud } \\
\hline REGIÓN & 1997 & 2001 \\
\hline 5 & $9,7 \%$ & $11,1 \%$ \\
8 & $14,5 \%$ & $15,6 \%$ \\
9 & $11,3 \%$ & $7,8 \%$ \\
13 & $29,0 \%$ & $34,4 \%$ \\
\hline Total & $100,00 \%$ & $100,00 \%$ \\
Profesional & \multicolumn{2}{|c|}{} \\
\hline Matrícula $1^{\circ}$ & \multicolumn{2}{|c|}{ Salud } \\
\hline REGIÓN & 1997 & 2001 \\
\hline 5 & $13,31 \%$ & $9,10 \%$ \\
8 & $7,70 \%$ & $18,16 \%$ \\
9 & $0,00 \%$ & $5,72 \%$ \\
13 & $44,00 \%$ & $42,08 \%$ \\
\hline Total & $100,00 \%$ & $100,00 \%$ \\
Profesional & & \\
\hline
\end{tabular}




\begin{tabular}{|c|cc|}
\hline $\begin{array}{c}\text { Oferta } \\
\text { programas }\end{array}$ & \multicolumn{2}{|c|}{ Educación } \\
\hline REGIÓN & 1997 & 2001 \\
\hline 5 & $17,3 \%$ & $18,7 \%$ \\
8 & $14,5 \%$ & $13,1 \%$ \\
9 & $5,2 \%$ & $4,6 \%$ \\
13 & $41,5 \%$ & $41,3 \%$ \\
\hline Total & $100,00 \%$ & $100,00 \%$ \\
Profesional & \multicolumn{2}{|c|}{} \\
\hline Matrícula $1^{\circ}$ & \multicolumn{2}{|c|}{ Educación } \\
\hline REGIÓN & 1997 & 2001 \\
\hline 5 & $16,50 \%$ & $15,85 \%$ \\
8 & $7,11 \%$ & $11,25 \%$ \\
9 & $3,95 \%$ & $5,23 \%$ \\
13 & $50,61 \%$ & $48,78 \%$ \\
\hline Total & $100,00 \%$ & $100,00 \%$ \\
profesional & & \\
\hline
\end{tabular}

\begin{tabular}{|c|c|c|}
\hline $\begin{array}{c}\text { Oferta } \\
\text { programas }\end{array}$ & \multicolumn{2}{|c|}{ Tecnología } \\
\hline REGIÓN & 1997 & 2001 \\
\hline 5 & $17,4 \%$ & $14,0 \%$ \\
\hline 8 & $11,1 \%$ & $13,8 \%$ \\
\hline 9 & $3,6 \%$ & $3,8 \%$ \\
\hline 13 & $36,6 \%$ & $32,9 \%$ \\
\hline $\begin{array}{l}\text { Total } \\
\text { profesional }\end{array}$ & $100,00 \%$ & $100,00 \%$ \\
\hline Matrícula $1^{\circ}$ & \multicolumn{2}{|c|}{ Tecnología } \\
\hline REGIÓN & 1997 & 2001 \\
\hline 5 & $11,14 \%$ & $13,65 \%$ \\
\hline 8 & $11,84 \%$ & $13,15 \%$ \\
\hline 9 & $0,85 \%$ & $5,13 \%$ \\
\hline 13 & $52,99 \%$ & $42,51 \%$ \\
\hline $\begin{array}{l}\text { Total } \\
\text { profesional }\end{array}$ & $100,00 \%$ & $100,00 \%$ \\
\hline
\end{tabular}

Entre las regiones que presentan una mayor dinámica se encuentra la $\mathrm{V}^{\mathrm{a}}$, que demuestra pérdidas significativas en cuanto a su participación en la oferta de algunas áreas e incrementos en otras. Así, en administración y comercio, humanidades y tecnología, esta región muestra una pérdida de oferta considerable respecto de 1997; en cambio, gana participación porcentual en materia de oferta en el área de derecho.

La IX ${ }^{a}$ pierde participación en la oferta de programas, en las carreras de Arte y Arquitectura, Ciencias y Salud.

La VIII ${ }^{a}$, por su parte, presenta bajas significativas en la participación de la oferta existente en las áreas agropecuaria, arte y arquitectura, y ciencias; por el contrario, registra incrementos en el área de tecnología.

Finalmente, en la región metropolitana, se aprecian decrementos en la participación de la oferta en ciencias sociales y tecnología, mientras aumenta su participación en el número de programas ofrecidos en las áreas de arte y arquitectura, humanidades y salud. 
En materia de participación en la matrícula de primer año, las regiones más dinámicas son la $\mathrm{V}^{\mathrm{a}}$ y la metropolitana. En la $\mathrm{V}^{\mathrm{a}}$ se observa un incremento de esta participación en el área ciencias, que tiene como correlato una baja en humanidades. No obstante, los cambios más notorios en este aspecto se producen en la región metropolitana, con decrementos en la participación de la matrícula en todas sus áreas, seis de las cuales: (administración y comercio, arte y arquitectura, ciencias, ciencias sociales, humanidades y tecnología) presentan una variación a la baja superior a los dos puntos porcentuales.

Las áreas más dinámicas en materia de matrícula de primer año, con variaciones por sobre los dos puntos porcentuales, son las de ciencias, ciencias sociales y humanidades. En las dos primeras se pueden observar, además de la señalada baja en la región metropolitana, incrementos en las regiones $\mathrm{V}^{\mathrm{a}}, \mathrm{VIII}^{\mathrm{a}}$ y $\mathrm{IX}^{\mathrm{a}}$. En el caso del área de humanidades, a la baja de la región metropolitana se suma un descenso de la $V^{a}$ y de la $I^{a}$, mientras que la VIII ${ }^{a}$ presenta en cambio un incremento en su participación del 2,58\% al 5,27\%. Si bien esta última observación no explica por sí sola los fuertes decrementos de la participación en la matrícula de primer año que presentan las áreas metropolitana y $\mathrm{V}^{\mathrm{a}}$, puede constituir un antecedente digno de atención.

\section{CONCLUSIONES}

A manera de conclusión y luego de la revisión descriptiva de lo que sucede en las áreas más dinámicas en materia de crecimiento, ya sea en su oferta o en la cantidad de alumnos que poseen en primer año, podemos constatar algunos hechos generales:

Primero: la heterogeneidad en el comportamiento de las distintas áreas observadas en materia del crecimiento de su oferta. Tomando como parámetro al indicador general de la evolución en la oferta de carreras en todas las áreas, podemos señalar que su amplitud de rango es notoria, aunque siempre con cifras positivas. Esta situación permite afirmar que en el periodo acotado, si bien todas las áreas crecen, lo hacen con ritmos distintos.

Segundo: una situación similar se presenta con respecto a los indicadores de matrícula de primer año, y en torno al indicador general 
de crecimiento en el periodo se observa la misma heterogeneidad en materia de ritmos y crecimientos.

Tercero: no necesariamente existe un correlato lógico entre el ritmo de crecimiento que manifiesta un área en términos del número de programas que articulan su oferta, y el número de estudiantes que se matricula en primer año. Resulta ilustrativo que el área de educación manifieste claramente un bajo ritmo de aumento de la oferta, por debajo del indicador general, mientras que en materia de matrícula de primer año muestra crecimientos superiores en más de 5\% sobre el indicador general. Sin embargo, el caso antes citado es una excepción, posible de explicar porque las carreras del área educación pueden flexibilizar su oferta de vacantes en torno a programas ya establecidos, debido a las facilidades que presentan en materia de implementación y equipamiento.

Cuarto: la misma heterogeneidad ya señalada existe al interior de las subáreas que articulan las diversas áreas temáticas, con la diferencia de que en este análisis se comprueban francos decrementos en algunas subáreas específicas, como asimismo crecimientos exagerados en otras. Así lo demuestran las cifras que informan tanto la oferta de programas como el número de alumnos matriculados en primer año.

El análisis de las subáreas permite identificar algunos temas específicos cuyo crecimiento exagerado puede explicarse, entre otros elementos, debido a que determinadas disciplinas se han puesto de moda.

Quinto: en varias oportunidades el crecimiento de un área descansa principalmente en la realidad de una o dos subáreas, que en definitiva subsidian, de una manera u otra, el incremento del área en la cual se incluyen, evitando muchas veces que el indicador del área se desplome. En materia de matrícula de primer año, éste es el caso de la subárea de turismo y hotelería, integrante del área de administración y comercio.

Sexto: es evidente que las diferencias de ritmos de crecimiento entre las áreas se traducen en cambios en la participación porcentual, tanto en la oferta total de programas existentes, como en el número 
general de alumnos que cursan estudios superiores de primer año. Los casos más notables respecto a cambios de participación para uno $\mathrm{u}$ otro indicador, corresponden al incremento del área tecnología y a la baja en administración y comercio.

Séptimo: algunas áreas temáticas presentan una clara sensibilidad a la incidencia del tipo de institución de educación superior que ofrece sus programas. Es así como, además de constatar el monopolio casi natural que existe en torno a algunas áreas por parte de las universidades, podemos identificar también áreas que, a través de subáreas específicas, manifiestan una particular sensibilidad a la incidencia que en ellas puede tener la acción de los institutos profesionales.

Octavo: en materia de sectores de supervisión, además del progresivo proceso de autonomía de la oferta y de la matrícula de primer año, se pone de manifiesto la agresividad con la cual los sectores de reciente autonomía comienzan a incrementar significativamente su participación, a través del manejo de la oferta, en desmedro de las instituciones tradicionales de educación superior.

Finalmente: la forma en que se distribuye la oferta temática de carreras, así como la manera en que reacciona la matrícula de primer año frente a estos cambios de oferta, se muestra sensible a la variable regional, al menos en cuanto a la participación porcentual que en los últimos años refleja el total nacional. Por lo demás, los cambios más notorios se producen principalmente en aquellas regiones que concentran la actividad industrial y comercial.

A manera de cierre, valga la oportunidad para comentar que resulta necesario analizar la forma en que evoluciona la oferta en cada una de las áreas temáticas, puesto que la educación superior adquiere cada vez mayor importancia en la formación de recursos humanos estratégicos para el desarrollo del país. Siendo así, no puede resultar indiferente el tema de las materias en torno a las cuales Chile está formando profesionales, y en qué proporción. Por último, debemos señalar que, si bien el lapso analizado resulta breve para realizar un análisis acabado de tendencias, refleja empero la realidad de un momento álgido en el desarrollo del sistema de educación superior en nuestro país. 